\title{
Emergência de plântulas de Lulo (Solanum quitoense Lam.) em função do tempo de armazenamento
}

\section{Seedling emergence of the Lulo (Solanum quitoense Lam.) in storage time function}

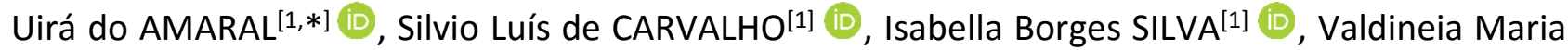
dos SANTOS ${ }^{[1]}$ (D) e Miquéias Gomes dos SANTOS ${ }^{[2]}$

[1] Faculdade de Filosofia e Ciências Humanas de Goiatuba (FAFICH). Rodovia GO 320, s/n, Bairro Jardim Santa Paula. CEP 75600-000. Goiatuba, GO, Brasil.silvio33carvalho@yahoo.com.br; isabellabsilva@outlook.com; valdineiaagm@gmail.com;

[2] Universidade Estadual Paulista (UNESP), Campus Jaboticabal. Via de Acesso Prof. Paulo Donato Castellane s/n. CEP 14884-900. Jaboticabal, SP, Brasil. miqueiasagronomia@gmail.com.

*Autor para correspondência: uiraagro@gmail.com INFORMAÇÃO RESUMO

Recebido em: 05/02/2016

Aceito em: 09/05/2016

Publicado em: 29/06/2016

Document Object Identifier

10.18067/jbfs.v3i2.89

1 crossref

Editor:

Victor Hugo G. Sales

jbfs@ifap.edu.br

ID JBFS0892016

Avaliação a cega por pares

Prot. 0892016R01

Prot. 0892016R02

Prot. 0892016R03

\section{cc) (i) (2)}

Copyright: (C) 2016
O Lulo (Solanum quitoense Lam) pertencente à família Solanaceae é originário de regiões Andinas e geralmente produz aproximadamente 1.000 sementes por fruto, sendo a reprodução sexuada a principal forma de propagação desta espécie. O presente estudo objetivou avaliar a influência do tempo de armazenamento na emergência de sementes de Lulo, oriundas de três épocas de colheita. $O$ experimento foi conduzido em delineamento inteiramente casualizado, com três tratamentos (3 meses, 6 meses e 12 meses de armazenamento) e sete repetições. As sementes foram semeadas em bandejas de poliestireno de 128 células em substrato comercial Bioflora ${ }^{\circledR}$. Observou-se que a qualidade fisiológica das sementes de Lulo decresceu significativamente quando armazenadas em sacos de papel em temperatura ambiente por período superior a seis meses. No entanto, não houve diferença significativa entre os tratamentos sobre a variável tempo médio de emergência. As variáveis analisadas apresentaram as maiores médias em sementes armazenadas por três meses, com destaque para emergência de aproximadamente $70 \%$.

Palavras-chave: Fisiologia de sementes. Frutas exóticas. Pequenos frutos

ABSTRACT - The Lulo (Solanum quitoense Lam.), belongs to the Solanaceae family originates from Andean regions, generally the fruits produces about 1.000 seeds and the sexual propagation the main form of propagation of the species. This study aimed to evaluate the influence of storage time in the emergency Lulo seeds from three harvest seasons. The experiment was conducted in a completely randomized design with three treatments (three months, six months and twelve months) and seven replications. The seeds were sown in polystyrene trays of 128 cells in commercial substrate Bioflora ${ }^{\circledR}$. It was observed that the physiological quality of seeds lobe decreased significantly when stored in paper sacks at room temperature for a period exceeding six months. However, there was no significant difference between treatments on the variable average time of emergency. The variables presented the highest averages for seeds stored for three months, especially for emergency approximately $70 \%$.

Keywords: Seed physiology, exotic fruits, small fruits.

Financiamento: Os autores reportam que não houve suporte e auxílio financeiro.

Conflito de interesse: Os autores declaram que não há conflito de interesse.

Como citar esse documento (ABNT):

AMARAL, U.; CARVALHO, S.L.; SILVA, I.B.; SANTOS, V.M.; SANTOS, M.G. Emergência de plântulas de (Solanum quitoense LAM.) em função do tempo de armazenamento. Journal of Bioenergy and Food Science, v.3, n.2, p.72-77, 2016. DOI:10.18067/jbfs.v3i2.89 


\section{INTRODUÇÃO}

O Lulo (Solanum quitoense Lam.) também conhecido por 'naranjilla' é uma planta arbustiva que produz frutos ricos em minerais e vitamina $C$. A espécie $S$. quitoense pertencente à família Solanaceae e é originário dos Andes, sendo bastante cultivada em países como Colômbia e Peru. $\mathrm{O}$ fruto apresenta um sabor agridoce, podendo ser consumido in natura ou processado na forma de sorvetes, geleias e doces. Além de suas características organolépticas, a polpa da fruta possui diversas propriedades antioxidantes, o que potencializa o consumo devido os benefícios à saúde humana. ${ }^{1}$

O fruto é uma baga globosa semelhante ao tomate, tem cor laranja quando maduro, de epicarpo grosso e coriáceo, com polpa verde-clara, pegajosa, ácida e suculenta, com grande número de sementes. Em geral, é possível encontrar em um fruto até 1.000 sementes podendo pesar entre $4 \mathrm{e}$ $40 \mathrm{mg}$, suas sementes são lisas e redondas. ${ }^{2,3}$

A propagação do Lulo pode ser efetuada tanto via sexuada (sementes), quanto por propagação assexuada (estacas e enxertia)., ${ }^{4,5}$ Diante disto, a produção de mudas de Lulo por sementes pode alavancar o cultivo desta espécie, pela quantidade de novos indivíduos produzidos e o baixo custo.

Depois de colhidas as sementes devem ser armazenadas adequadamente, a fim de reduzir ao mínimo o processo de deterioração. As condições fundamentais para o armazenamento das sementes são a umidade relativa do ar e a temperatura do ambiente de armazenamento. Estes fatores podem influenciar no armazenamento de sementes em função das características fisiológicas das sementes, as quais são classificadas em ortodoxas ou recalcitrantes. ${ }^{6}$

Durante o armazenamento, mesmo quando este procedimento é realizado em condições adequadas, as sementes continuam expostas ao processo de deterioração, pois o mesmo é inexorável e irreversível. ${ }^{7}$ Outra manifestação da deterioração durante o armazenamento tem sido a desestruturação do sistema de membranas, como consequência do ataque aos seus constituintes químicos pelos radicais livres. ${ }^{8}$
Existem poucas informações sobre a melhor forma de conservar a viabilidade das sementes de Lulo. Dentro da família Solanaceae é possível identificar algumas espécies com sementes ortodoxas, o Physalis angulata é um exemplo disto, ou seja, suas sementes toleram à secagem até níveis de baixos teores de água (variando de 4 a 12\%), o que favorece 0 armazenamento por longos períodos. ${ }^{9}$

O armazenamento pós-colheita dos frutos de tomate por 12 dias é benéfico à qualidade fisiológica das sementes apenas quando a colheita é realizada aos 40 dias após a antese (DAA), estando os frutos com coloração externa transitória do verde ao vermelho, sendo que sementes de elevada qualidade são obtidas de frutos colhidos aos 50 e 60 DAA e não armazenados. ${ }^{10}$

Neste sentido, o entendimento dos processos fisiológicos da semente submetidas a diferentes tempos de armazenamento é essencial para exploração racional desta espécie no país. Diante do exposto, o presente trabalho teve como objetivo avaliar a influência do tempo de armazenamento na emergência de sementes de Lulo.

\section{MATERIAL E MÉTODOS}

O experimento foi conduzido no município de Goiatuba, localizado na região Sul do Estado de Goiás, na área experimental da Faculdade de Filosofia e Ciências Humanas (FAFICH) (latitude $27^{\circ} 48^{\prime} 17^{\prime \prime}$ Sul e longitude $50^{\circ} 19^{\prime} 30^{\prime \prime}$ Oeste e altitude de $815 \mathrm{~m}$ ), em setembro de 2014. O clima da região é classificado como do tipo AW (Classificação de Köppen), caracterizado como tropical úmido, com duas estações bem definidas, úmida no verão e seca no inverno.

As sementes de Lulo (S. quitoense Lam) foram adquiridas da empresa Sambalina Sementes ${ }^{\circledR}$ localizada no município de Nova Petrópolis - RS. Já os dados médios de temperatura máxima $\left(29^{\circ} \mathrm{C}\right)$, média $\left(24^{\circ} \mathrm{C}\right)$ e mínima do ar $\left(19^{\circ} \mathrm{C}\right)$, referente ao período de condução do experimento foram obtidos junto ao Instituto Nacional de Meteorologia (INMET - Morrinhos/GO).

As sementes de Lulo foram acondicionadas em sacos de papel Kraft e mantidas em temperatura ambiente até o momento da instalação do experimento. Os frutos foram colhidos em três 
épocas diferentes (setembro de 2013, março de 2014 e junho de 2014) quando o pericarpo dos frutos apresentavam coloração alaranjada. As sementes foram semeadas em bandejas de poliestireno de 128 células em substrato comercial BioFlora ${ }^{\circledR}$ com a seguinte composição química: $\mathrm{CE}$ ( $\mathrm{mS} / \mathrm{cm}=1,20 \pm 0,3) ; \mathrm{pH}(6,0 \pm 0,5)$; umidade $(\% \mathrm{~m} / \mathrm{m}$ $=60)$; densidade $\left(\mathrm{kg} / \mathrm{m}^{3}=380\right)$; fertilizante $(\mathrm{m} / \mathrm{m}=$ $0,3$ a 0,9$)$; corretivo $(\mathrm{m} / \mathrm{m}=0,6$ a 0,9$)$ e CRA $(\% \mathrm{~m} / \mathrm{m})$ $=150$.

O experimento foi conduzido em telado coberto com tela preta $70 \%$ (sombrite), sendo utilizado o delineamento inteiramente casualizado, com três tratamentos ( 3 meses, 6 meses e 12 meses de armazenamento) e sete repetições e cada unidade experimental foi constituída de 24 sementes, totalizando 504 sementes. As variáveis analisadas foram as seguintes:

\section{A) Porcentagem de emergência (PE)}

Determinada por meio da contagem de plântulas emergidas (folhas cotiledonares expandidas) até o décimo quinto dia de avaliação.

B) Índice de velocidade de emergência (IVE)

A contagem de plântulas emergidas foi realizada diariamente determinando-se 0 índice de velocidade de emergência ${ }^{11}$, conforme a equação 1 :

$I V E=\frac{N 1}{D 1}+\frac{N 2}{D 2}+\cdots+\frac{N n}{D n}$

Onde:

$\mathrm{N}=$ número de plântulas emergidas e computadas da primeira à última contagem;
$\mathrm{D}=$ número de dias da semeadura da primeira à última contagem.

\section{C) Tempo médio de emergência (TME)}

Expresso em dias, calculado de acordo com $^{12}$, expresso pela equação 2 :

$T M E=(\Sigma n i t i) / \Sigma n i)$

onde:

$\mathrm{ni}=$ número de sementes germinadas por dia;

$\mathrm{ti}=$ tempo de incubação;

$\mathrm{i}=15$ dias.

Os dados foram submetidos à análise de variância por meio do teste $F$, e as médias foram comparadas pelo teste de média Tukey a $5 \%$ de probabilidade com auxílio do programa estatístico SISVAR. ${ }^{13}$

\section{RESULTADOS E DISCUSSÃO}

Conforme o resultado da análise de variância houve efeito significativo ao nível de $5 \%$ de probabilidade dos tratamentos sobre as variáveis porcentagem de emergência e índice de velocidade de emergência, com exceção da variável tempo médio de emergência (TME) (Tabela 1).

As sementes armazenadas por 3 meses em sacos de papel Kraft, apresentaram valores superiores para variável porcentagem de emergência, com valor médio de $67 \%$ (Figura 1). Ao passo que as sementes foram armazenadas por maiores períodos 6 meses e 12 meses, menor foi a porcentagem de emergência, 39\% e 7,7\%.

Tabela 1. Resumo da análise de variância para as variáveis: porcentagem de emergência (\%), tempo médio de emergência (TME) e índice de velocidade de emergência (IVG).

Table 1. Summary of the analysis of variance for the variables: percentages of emergency (\%), mean emergence time (days) and Index of germination speed (GSI).

\begin{tabular}{lccc} 
& \multicolumn{3}{c}{ Quadrados médios } \\
\cline { 2 - 4 } Fontes de Variação & $\begin{array}{c}\text { Porcentagem de } \\
\text { emergência } \\
\text { (PE) }\end{array}$ & $\begin{array}{c}\text { Tempo médio de emergência } \\
\text { (TME) }\end{array}$ & $\begin{array}{c}\text { Índice de velocidade de } \\
\text { emergência } \\
\text { (IVE) }\end{array}$ \\
\hline Tratamento & $7702,05^{*}$ & $0,95^{\text {ns }}$ & $81,57^{*}$ \\
Erro & 212,75 & 0,55 & 15,20 \\
\hline CV (\%) & 38,45 & 10,31 & 93,67 \\
Média Geral & 37,94 & 7,18 & 4,16 \\
\hline
\end{tabular}

*DMS - diferença mínima significativa, $p<0,05$. ns - não significativo. CV - coeficiente de variação

*LSD - least significant difference, $p<0.05$. ns - non significant. CV - coefficient of variation 


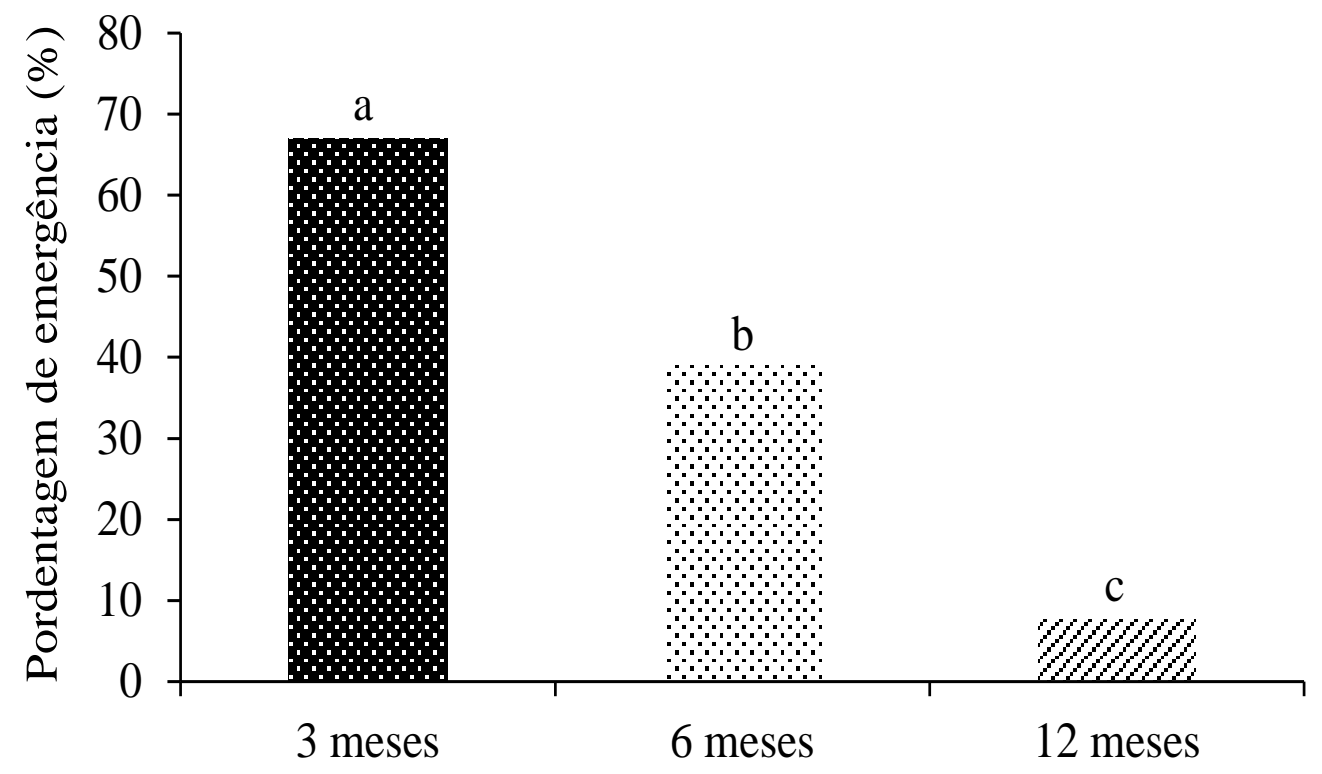

Tempo de armazenamento

Figura 1. Porcentagem de emergência de sementes de Lulo (S. quitoense) em função do armazenamento. Letras maiúsculas diferentes nas colunas indicam diferença significativa pelo teste Tukey $(\mathrm{P}<0,05)$.

Figura 1. Percentages of emergence of Lulo (S. quitoense) due storage. Different lowercase letters in the same column differ by Tukey test $(p \leq 0.05)$.

Segundo Delouche e Baskin, ${ }^{14}$ o decréscimo do potencial de armazenamento é uma das manifestações fisiológicas mais comuns. Assim, o armazenamento de sementes assume papel importante no processo produtivo e, quando bem conduzido, minimiza a deterioração e o descarte de lotes de sementes.

Neste sentido, considerando a qualidade fisiológica e o armazenamento de sementes de diferentes cultivares de feijoeiro, observou-se a redução da qualidade fisiológica por período superior a doze meses. ${ }^{15}$ Por outro lado, sementes de Physalis angulata L. sob pré-condicionamento osmótico apresentaram taxas de germinação e índice de velocidade de germinação elevadas em ambiente quando osmocondicionadas até 24 meses. ${ }^{9}$

O tempo médio de emergência relaciona-se à emergência das sementes e estabelecimento das plântulas em campo, quanto mais rápida for essa emergência menos tempo a semente ficará exposta a possíveis fatores ambientais adversos como déficit ou excesso de água, temperaturas inadequadas do solo, presença de patógenos. ${ }^{16}$

Mesmo não havendo diferença significativa entre as épocas avaliadas para variável tempo médio de emergência (TME), o armazenamento de sementes de Lulo por período superior a 12 meses pode alterar significativamente aspectos fisiológicos que garantem uma boa emergência (Tabela 1). Em seus estudos Bezerra et al., ${ }^{17}$ avaliando a germinação e o desenvolvimento de plântulas de melão-de-são-caetano em diferentes ambientes e substratos, observaram que o TME foi inferior em condições naturais aquele verificado em germinador para todos os substratos, chegando a 17 dias quando colocado em germinador.

Em estudo testando diferentes metodologias para avaliação da qualidade fisiológica de sementes de cenoura cultivar Londrina armazenada por dez anos, o vigor das sementes refletiu no tempo médio de emergência (TME), apresentando resultados desfavoráveis para o lote de 1998, o que também foi observado para as demais metodologias, ou seja, as 


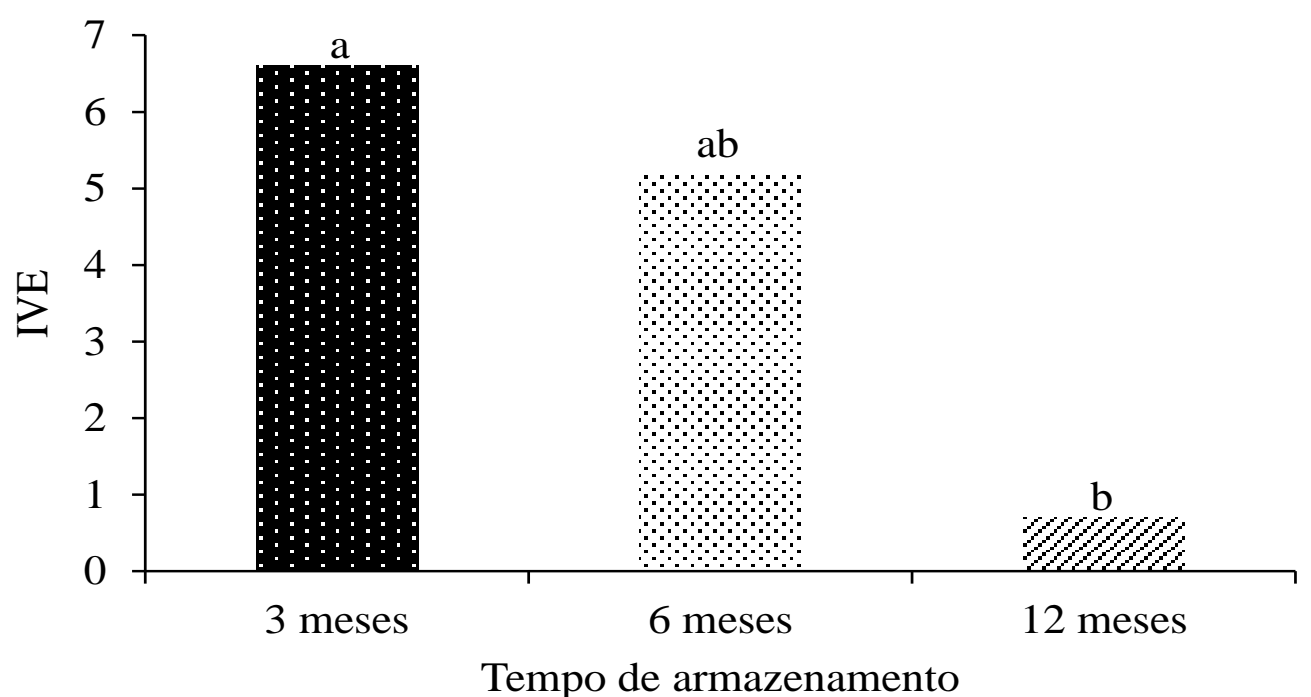

Figura 2. Índice de velocidade de emergência (IVE) de Lulo (S. quitoense) em função do armazenamento. Letras minúsculas diferentes nas colunas indicam diferença significativa pelo teste Tukey $(P<0,05)$.

Figure 2. Index of germination speed (GSI) of Lulo (S. quitoense) due storage. Different lowercase letters in the same column differ by Tukey test ( $p \leq 0.05)$.

sementes de menor qualidade, com maior período de armazenamento, demandaram maior tempo para germinarem. ${ }^{18}$

Com relação ao índice de velocidade de emergência (IVE) as sementes armazenadas por 3 meses apresentaram valor igual a 6,6. As sementes armazenadas por 12 meses apresentaram menor valor médio de IVE $(0,7)$.

Em um estudo desenvolvido com envelhecimento acelerado de sementes de cubiu (Solanum sessiliflorum Dunal), foi observado que o IVG apresentou valor de 6,83 (lote 3 ) nas condições de 41 으, por 72 ou 96 horas. Portanto, as sementes de cubiu quando submetidas ao teste de envelhecimento acelerado, apresentaram aumento considerável da taxa de deterioração, por meio da exposição a níveis muito adversos de temperatura e umidade relativa. ${ }^{19}$

As sementes de Lulo quando armazenadas em sacos de papel Kraft em temperatura ambiente por período superior a 6 meses apresentaram diminuição dos valores médios de porcentagem de emergência e o índice de velocidade de emergência. Por outro lado, ainda são necessários estudos mais detalhados sobre a fisiologia da semente desta espécie ainda pouco estudada no Brasil.

\section{CONCLUSÃO}

Com exceção do tempo médio de emergência as demais variáveis analisadas foram influenciadas pelos diferentes tempos de armazenamento. Sugere-se ainda que seja estendido o período de avaliação da emergência das plântulas.

As sementes armazenadas em sacos de papel e mantidas em temperatura ambiente por período de até três meses apresentaram a maior porcentagem de emergência.

\section{AGRADECIMENTOS}

À empresa Sambalina Sementes ${ }^{\circledR}$ pela disponibilidade das sementes e pelas orientações da proprietária Verônica Bruch.

\section{CONTIBUIÇÃO DOS AUTORES}

\section{Desenvolvimento e condução do experimento; Elaboração do artigo científico.}

Uirá do Amaral ${ }^{(D)}$; Silvio Luis de Carvalho ${ }^{(D)}$; Isabella Borges Silva ${ }^{(D)}$ Valdineia Maria dos Santos (D) Miquéias Gomes dos Santos (iD). 


\section{REFERÊNCIAS BIBLIOGRÁFICAS}

1. ANDRADE-CUVI, M.J.; MORENO-GUERRERO, C.; GUIJARRO-FUERTES, M.C.A. Caracterización de la naranjilla (Solanum quitoense) comun en tres Estados de Madurez. Revista Iberoamericana de Tecnologia Postcosecha, v. 16, n.2, p.215-221, 2015. redalycs

2. MATARAZZO, P.H.M.; SIQUEIRA, D.L. de; SALOMAO, L.C.C.; SILVA, D.F.P. da; CECON, P.R. Desenvolvimento dos frutos de Lulo (Solanum quitoense LAM), em Viçosa-MG. Revista Brasileira de Fruticultura, v.35, n.1, p.131-142, 2013. Crossref

3. GÓMEZ-MERINO, F.C.; TREJO-TÉLLEZ, L.I.; GARCIAALBARADO, J.C.; CADEÑA-ÍNIIGUEZ, J. Lulo (Solanum quitoense [Lamarck.]) como cultivo novedoso en el paisaje agroecosistémico mexicano. Revista Mexicana de Ciências Agrícolas, n.9. p. 1741- 1753, 2014. redalyc.sg

4. MACHADO, D.L.M.; AGUIAR, A.S.; OLIVEIRA, R.C. de; LIMA, D.T. de. Deficiência induzida de nitrogênio, fósforo e potássio em mudas de Lulo. Scientia Agrarian Paranaensis, v.15, n.1, p.78-81, 2016. Crossref

5. JURAdO, C. J. C.; PÉREZ, H. L. J.; LAGOS, B. T. C.; BERNARDES, C. C. A. Comportamiento agronómico de injertos de Lulo de castilla Solanum quitoense Lam. en patrones de Solanum ssp. Revista de Ciencias Agrícolas, v.30, n.1, p.54-64, 2013.

6. VIEIRA, R.D.; TEKRONY, D.M.; EGLI, D.B.; RUCKER, M. Electrical conductivity of soybean seeds after storage in several environments. Seed Science and Technology, v.29, n.3, p.599-608, 2001

7. CANTOS, A.A.; TUNES, L.M.; BARBIERI, A.P.P.; TAVARES, L.C. Avaliação de testes de vigor em sementes de aveia branca (Avena sativa L.). Revista da FZVA, v.18, n.2, p.111, 2011.

8. JOSÉ, S.C.B.R.; SALOMÃO, A.N.; COSTA, T. da S.A.; SILVA, J.T.T.T da, CURI, C. C. da S. Armazenamento de sementes de girassol em temperaturas subzero: aspectos fisiológicos e bioquímicos. Revista Brasileira de Sementes, v.32, n.4, p.29-38, 2010. Crossref

9. SOUZA, M.O. de; SOUZA, C.L.M. de; BARROSO N. dos S.; PELACANI, C.R. Preconditioning of Physalis angulata L. to maintain the viability of seeds. Acta Amazonica, v. 44, n. 1, p. 153-156. 2014. Crossref
10. VIDIGAL, D. de S.; DIAS, D. C. F. dos S.; NAVEIRA, D. dos S. P. C.; ROCHA, F. B.; BHERING, M. C. Qualidade fisiológica de sementes de tomate em função da idade e do armazenamento pós-colheita dos frutos. Revista Brasileira de Sementes, v.28, n.3, p.87-93, 2006. Crossref

11. MAGUIRE, J.D. Speed of germination-and in selection and evaluation for seedling emergence and vigor. Crop Science, v.2, n.2, p.176-177. 1962.

12. LABOURIAU, L.F.G. A Germinação de sementes. Washington: Organização dos Estados Americanos, 174p. 1983.

13. FERREIRA, D. F. Análises estatísticas por meio do Sisvar para Windows versão 4.0. In: Reunião Anual da Região Brasileira da Sociedade Internacional de Biometria. Anais... São Carlos, UFSCar, p. 255-258. 2000.

14. DELOUCHE, J.C.; BASKIN, C.C. Accelerated aging techniques for predicting the relative storability of seeds lots. Seed Science and Technology, v.1, n.2, p.427-452. 1973.

15. SILVA, M.M. da; SOUZA, H.R.T de; DAVID, A.M.S de S.; SANTOS, L.M. dos; SILVA, R.F.; AMARO, H.T.R. Qualidade fisiológica e armazenamento de sementes de feijãocomum produzidas no norte de Minas Gerais. Revista Agro@mbiente On-line, v.8, n.1, p.97-103, 2014.

16. GAZOLA, R. de N.; CASTILHO, R.M.M. de; DINALLI, R.P.; CELESTRINO, T. de S.; MÓDENA, C.M. Germinação e crescimento inicial de plântulas de pepino em substratos comerciais. Tecnologia \& Ciência Agropecuária, v.7, n.3, p.25-30, 2013

17. BEZERRA, A. M. E.; MOMENTÉ, V. G.; ARAúJO, E. C. de; MEDEIROS FILHO, S. Germinação e desenvolvimento de plântulas de melão-de-são-caetano em diferentes ambientes e substratos. Ciência Agronômica, v.33, n.1, p.39-44, 2002.

18. ORTIZ, T.A.; LONE, A.B.; UNEMOTO, L.K.; ATHANÁZIO, J.C.; TAKAHASHI, L.S.A. Metodologias para avaliação da qualidade fisiológica de lotes de sementes de cenoura cultivar Londrina armazenados por até dez anos. Bioscience Journal, v. 30, sup, p.330-337, 2014.

19. PEREIRA, M.D.; MARTINS FILHO, S. Envelhecimento acelerado em sementes de cubiu (Solanum sessiliflorum Dunal). Pesquisa Agropecuária Tropical, v. 40, n. 3, p. 251-256. 2010. redalyo. 